\title{
ENTREVISTA COM DONALDO SCHÜLER
}

Leide Daiane de Almeida Oliveira ${ }^{1}$

Larissa Ceres Lagos ${ }^{2}$

Giovana Beatriz Marique Ursini ${ }^{3}$

$122^{3}$ Universidade Federal de Santa Catarina, Florianópolis, Santa Catarina, Brasil

Donaldo Schüler é professor titular aposentado em Língua e Literatura grega da UFRGS, além de ser poeta, ensaísta e tradutor. Sua carreira como tradutor conta com traduções de tragédias gregas, a Odisséia de Homero e Finnegans Wake de James Joyce, entre outras. Sua tradução da última obra de Joyce, em edição bilíngue, Finnegans Wake/Finnicius Revém, publicada em cinco volumes, (1999-2003) lhe rendeu o prêmio Jabuti em 2004. Schüler traz a narrativa joyceana para o Brasil. Em entrevista concedida a Marie-Hélène Torres e Mauri Furlan, em 2004, publicada em 2010 na revista Scientia Traductionis, Schüler fala sobre o processo de tradução como um processo de produção: "O texto traduzido provoca o renascimento do texto de origem em outro lugar, em outra cultura. Não se concebe tradução literária sem produção literária. Traduzir é produzir. Quem traduz entra no processo da produção" (Schüler 315). É principalmente sobre sua experiência como tradutor de Finnegans Wake, um dos livros mais desafiadores da literatura ocidental, que essa entrevista se propõe dedicar maior atenção. Além de ser um renomado tradutor, sua vasta produção conta ainda com ensaios, entre eles: Teoria do romance (1989), Eros: dialética e retórica (1992), Narciso Errante (1994), Heráclito e seu (dis)curso e Origens do discurso democrático (2000), Na conquista do Brasil (2001), Origens do discurso democrático (2002), Fronteiras e confrontos (2009), Afrontar fronteiras, (2012), entre 
outros. Como ficcionista publicou os seguintes romances: $A$ mulher afortunada (1982), Faustino (1987), Pedro de Malasartes (1992), ) O homem que não sabia jogar (1998), apenas para citar alguns. Seu livro mais recente Joyce era Louco? foi publicado em 2017. Nesta obra, ele discute, entre outras coisas, o tema da loucura e suas relações com a inventividade literária. Donaldo Schüler possui amplo reconhecimento da sua contribuição como escritor, crítico literário, professor e tradutor, tendo recebido muitos prêmios ao longo de sua prolífera carreira. Schüler nasceu em 1932, em Videira, Santa Catarina, e em 2002 recebeu o Título Honorífico de Cidadão de Porto Alegre. Foi também em Porto Alegre que Schüler realizou grande parte de sua formação acadêmica. Seu doutorado e livre-docência são pela UFRGS e pela PUCRS. Detentor de uma fascinante erudição, percebida tanto em seus livros quanto em suas palestras, demonstra ainda uma fluência impressionante em vários idiomas, entre elas estão o grego, o alemão e o francês.

Cadernos de Tradução (CT): Como começou sua trajetória como tradutor?

Donaldo Schüler (DS): Então vamos começar desde o início. Bom, eu fui professor na Federal do Rio Grande do Sul, e nos anos 1960 foi traduzido o Ulysses por Antônio Houaiss, pois bem, eu lecionava literatura grega, então eu levei os meus alunos a fazerem estudos comparativos entre Ulysses e a Odisseia, começou por aí. Depois eu fui professor de teoria da literatura comparada, isso estava em desenvolvimento na época, então eu dei cursos sobre literatura comparada. Porto Alegre é uma cidade em que a sociedades psicanalíticas lacanianas são muito atuantes. E uma dessas sociedades me pediu que eu desse seminários sobre o Finnegans Wake e o que nós tínhamos na época era o Panaroma de Haroldo de Campos. Então se verificou que não era suficiente para ter uma visão mais ampla do romance e eles me pediram para traduzir. Então tratei de adquirir a bibliografia que existia sobre o Finnegans Wake. Bem, 
eu já tinha contato com Haroldo de Campos e com a teoria de tradução do Haroldo de Campos e eu comecei a traduzir por essa finalidade. Quando a tradução estava em andamento, nós entramos em contato com a Ateliê, com o editor da Ateliê Plínio Martins, e ele aceitou a publicação e então publicamos em cinco volumes. Saiu em primeiro lugar o primeiro capítulo, e depois, publicamos mais quatro. Então, a pré-história é essa.

\section{CT: Quanto tempo de trabalho de uma publicação a outra?}

$D S$ : Eu estou em contato com o Joyce desde os anos 1960. Me interessava as vanguardas, eu lia Ezra Pound, lia o que os irmãos Campos publicavam, acompanhei o movimento concretista em São Paulo e então, o contato é desde 1960, mas quando resolvi mesmo traduzir o Finnegans Wake (são 628 páginas) tomei a decisão de traduzir uma página por dia, isso descontando fins de semana, férias, etc., e isso me tomou uns quatro anos. Porque senão a gente desespera porque efetivamente ele trabalha com 60 mil verbetes, quando você vê aquele calhamaço de coisas... Então para não desesperar, fiz esse planejamento. E por isso também publicamos por parte, à medida que eu ia traduzindo, fomos publicando.

CT: Você comentou sobre a tradução de Ulysses realizada por Antônio Houaiss, nos anos 1960, com a qual teve contanto. Desde então tivemos mais duas traduções, da Bernadina da Silveira Pinheiro e a do Caetano Galindo. O que você acha sobre retradução de uma obra literária?

$D S$ : Bom, eu trabalhei bastante com o Antônio Houaiss. Já escrevi sobre essas traduções. Me parece que a tradução da Bernadina é a mais espontânea, ela não tem uma preocupação literária, ela procurou fazer uma tradução fácil e de fato ela é muito mais legível 
do que a de Antonio Houaiss que é uma tradução mais rebuscada. Mas, se a gente se detém com mais bagagem, aí aparecem algumas questões, agora, cada tradução depende dos objetivos, mas alguns detalhes que são importantes para a interpretação do Ulysses não foram considerados com atenção por nenhum dos tradutores. Dou um exemplo: No primeiro capítulo há uma cena em que o Buck Mullingan pega o Stephen Dedalus e põe dentro do espelho e diz olha para essa sua cara de cachorro, e há toda uma encenação com a eucaristia já desde o início. E se fala em tão no God's body, no corpo de Deus, que é a eucaristia, e em inglês God, vejam, ele coloca a face do Stephen Dedalus no espenho, o espelho inverte. Se você coloca God no espelho, dá $\operatorname{dog}$. Então olha para essa sua cara de cachorro, invertido dá Deus. E o Antônio Houaiss traduz isso por canicarcaça e é um eruditismo. Dog's body ou God's body é absolutamente coloquial. Quer dizer então que essa inversão de Dog's body, porque, enfim, o que é o Stephen Dedalus? Algo que está entre o cachorro e Deus! Essa brincadeira é muito joyceana. Pois bem, nenhuma das traduções observa essa situação. Essa mesma brincadeira ele faz em algum lugar no Finnegans Wake. Então se eu disser que meu cachorro se chama Sued, isso não espanta ninguém, não é? Mas Sued é deus no espelho. Você pega Deus e dá cachorro. Olha para essa sua cara de sued, meu cachorro se chama sued, então tem que se dar um jeito na tradução para trazer isso. $\mathrm{Na}$ tradução você tem que inventar coisas. Se você encontra um negócio desses, bom, isso aqui não dá pra traduzir, então vai canicarcaça, aí não dá. O trabalho do tradutor é encontrar soluções. Haroldo de Campos dizia que os únicos textos que devem ser traduzidos são os intraduzíveis, aí você tem que inventar. Pois bem, assim existem várias situações que aparecem na tradução e que não se dá atenção. Então, se a Bernadina quer fazer uma tradução fácil, coloquial, então, você está lendo o quê? Está lendo banalidade. Uma brincadeira que é fundamental para o livro, some.

CT: Será que não é o caso dessa questão ter escapado ao tradutor?

Cad. Trad., Florianópolis, v. 39, no 2, p. 294-304, mai-ago, 2019. 
$D S$ : A gente não percebe tudo. Também é questão de saber isso. Porque o Antônio Houaiss efetivamente esteve na Inglaterra, ele dominava muito bem a língua inglesa. Eu uso muito a tradução do Antônio Houaiss e o Galindo tem coisas muito boas. Quero dizer, é boa? É má? Cada uma tem suas características e existem alguns elementos que precisam ser resolvidos. Até poderia se pensar em entrar em contato com os tradutores e chamar atenção para certos jogos de linguagem.

CT: Pensando sobre sua tradução do Finnegans Wake, é perceptível que você traz as referências para o Brasil. Você poderia justificar suas escolhas?

$D S$ : Sim, até a Bahia. Porque no inglês é "caminhos de Vico", quando eu resolvi botar esse Finnegans Wake na Bahia, e escrevo Bahia com H, então ao invés de caminhos uso cominhos, cominhos dá condimentos. São criações que não tem nada a ver com Joyce. Mas a minha posição é criar um Finnegans Wake brasileiro.

CT: Sim, seu projeto é esse: um Finnegans Wake brasileiro, mas essa decisão foi anterior ao início da tradução?

$D S:$ Não... Bem, eu estava preocupado com a tradução e a teorização de Augusto de Campos foi fundamental. Ele refletiu sobre a tradução e o Haroldo de Campos teve influência sobre toda uma geração de tradutores. Esse princípio do Ezra Pound, do make it new, torne-o novo, esse processo de renovação. Quer dizer, você tem um compromisso como texto original, mas a tradução tem que funcionar na língua que recebe. Pra evitar isso, diminuir a tradução, você tem que colocar notas de pé de página. Em Finnegans Wake você teria que fazer uma nota de pé de página muito maior que o próprio livro... Então, qual é o sentido? Muito bem, se você não fizer isso... Ele mistura 60 línguas, então leia em inglês, dessa forma efetivamente 
é intraduzível como diz muita gente. Assim você resolve traduzir o intraduzível. O lucro que você tem como tradutor evidentemente é muito grande. Você é obrigado a inventar, quer dizer, quem não é poeta tem que virar poeta. É uma escola de a gente se tornar poeta. Não é um livro científico, não tem um compromisso com os conceitos, mas enfim, mas com os processos de transformação.

CT: Embora a gente sempre escute que o livro é intraduzível, Joyce incentivava a tradução e inclusive participava da tradução pra outros idiomas...

$D S$ : Principalmente o capítulo oito que ele acompanhou a tradução para o italiano.

CT: Diante das inúmeras dificuldades que o Finnegans Wake impõe, é possível que o tradutor considere desistir de determinada tradução? Você pensou em abandonar o projeto e não terminar a tradução?

$D S$ : Veja, aí a sociedade psicanalítica não me deixava fazer isso (risos) quer dizer, uma vez que eu havia assumido o compromisso, não havia mais possibilidade de recuo. Mas quando eu assumi o compromisso eu sentia dificuldade e como eu estava resolvendo os problemas, achei que poderia ser levado até o fim, mas não me ocorreu a ideia de abandonar o projeto. Tive relutância em aceitar o projeto, mas uma vez que tinha começado "então vamos até o fim”. Tinha um compromisso com o editor também, quer dizer eu tinha me comprometido a traduzir um capítulo e agora terminou por que o tradutor não quer mais? (Risos)

CT: Você ficou satisfeito com o resultado da tradução? É uma coisa que a gente comenta bastante, principalmente depois que 
passa, que a gente entrega e pensa "puxa, poderia ter feito isso diferente ou não"...

$D S$ : Veja, isso acontece sempre. Mas essa inquietação você tem com respeito aos próprios escritos, que você escrever. Deve chega um momento que você diz "bom, agora terminou" caso contrário você não publica nada e não escreve nada porque essa satisfação total não existe. E bom, a satisfação foi a seguinte: eu fiz o que eu pude fazer. Eu fiz, trabalhei com denodo e, como eu era professor de literatura e teoria da literatura, as teorias literárias eu conhecia bem. Eu já tinha escrito vários livros de ficção, então como criador de ficção e de poesia (publiquei um livro de poemas também) eu estava dentro desse clima.

Agora satisfação efetivamente, essa satisfação não vai terminar nunca, e se terminar você fica inútil, você não faz mais nada ( $r i$ sos). Escrever é uma coisa... Uma vez que a gente começa a escrever é um incômodo sempre porque a gente nunca está satisfeito. Mas se você não fizesse isso você se preocuparia com banalidades que você esquece... As coisas menos importantes deixam de ter o relevo que teriam se você não fizesse isso, essa inquietação é humana...

CT: Você acha que depois de passar por essa experiência de tradução com o Finnegans Wake, sua forma de traduzir, seu método de trabalho mudou?

$D S$ : Eu escrevi um livro de fábulas, eu traduzi, eu adaptei fábulas, eu criei fábulas de quem criou a fábula no ocidente que é um autor grego, Esopo. O meu livro de contos chama-se Refabular Esopo. Então... Veja o seguinte, pra eu dar um exemplo, tem um leão que se apaixona por uma cadela, os sentimentos que ele tinha pela cadela era uma cadelícia (risos). Coisas assim, evidentemente eu faço alguns jogos vocabulares como esse da cadelícia, mas não é na intensidade de Joyce. Enfim, Joyce é uma situação única. 
Essa brincadeira com palavras e jogos de palavras e sons, isso me preocupa, mas eu não tenho nenhuma intensão de imitar Joyce. Porque não se imita ninguém. Não se imita Dante, não se imita Shakespeare, Dante é Dante, Shakespeare é Shakespeare, e se a gente consegue fazer alguma coisa pequenininha, uma vírgula nessa história toda já é muita coisa, não é?

CT: O fato é que deve ficar um pouco, de tanto traduzir com os jogos...

$D S$ : Ah sim, não há dúvida nenhuma.

CT: Sobre a tradução e adaptação para o público infanto-juvenil do Finícius Rio-vem, como que surgiu essa ideia. Foi um convite? E como foi traduzir as temáticas presentes na obra?

$D S$ : Essa ideia me veio pela própria gênese, o Carroll é um dos autores que brincam com as palavras, e as crianças brincam com as palavras. Uma das minhas filhas, eu tenho três filhas, quando ela tinha uns dois anos, ao invés de buraquinho ela dizia furaquinho. É uma coisa fantástica, aparece espontaneamente. Então levar essa brincadeira para as crianças, inclusive esse livro, todos os livros as edições são pequenas, mas para as pessoas que leram o livro pegou bem... Então é um livro que pegou. Aí eu faço a mesma coisa: devolver à criança aquilo que veio da criança. Um processo de devolução para criança. Inclusive o próprio imaginário, se você se coloca na situação da criança, inclusive esse furaquinho eu aproveitei na própria tradução do Finnegans Wake, em algum lugar eu coloquei furaquinho.

CT: De que forma a sua carreira como professor, tradutor, poeta, escritor mudou depois do trabalho com Finnegans Wake. Nós

Cad. Trad., Florianópolis, v. 39, n 2, p. 294-304, mai-ago, 2019. 
assistimos um documentário algum tempo atrás sobre a Svetlana Gaier, que é a tradutora dos cinco romances que chamam de "cinco elefantes” do Dostoievski para o alemão. Nesse documentário, a fala dela nos deixa muito impactados. Ela, sobre as traduções, diz que "você não passa ileso por esses cinco livros". Gostaríamos que você comentasse um pouco sobre isso.

DS: Toda a minha produção literária sempre respondeu a solicitações. Eu traduzi também a Odisseia porque uma editora me pediu a tradução. Traduzi tragédias gregas com a mesma finalidade e os livros teóricos eram solicitações de sala de aula. Com essa experiência de aula eu tenho um sobre a teoria do romance, teorizava sobre o romance, quer dizer quando eu pensava em um curso eu já pensava nesse processo de transformação. Agora o que eu faço agora, depois que traduzi Finnegans Wake, com mais intensidade do que antes é misturar ensaio com ficção. Inclusive tenho um livro agora recente, Joyce era louco, nele faço uma aproximação de alguns capítulos do Ulysses, inclusive o monólogo da Molly Bloom, eu tenho umas nove páginas em que eu uso aquele processo de narrativa, agora ensaisticamente. Eu faço uma análise do capítulo dentro daquele processo narrativo da Molly Bloom. Quer dizer, são brincadeiras, mas isso tira a seriedade do ensaio. Existem ensaios muito acadêmicos que ninguém lê porque acha uma chatice... Esse ranço acadêmico.

A ficção não é um elemento de se aproximar da verdade. Você não atinge, na literatura, elementos que você consegue entender melhor se você faz uso uma linguagem puramente teórica. Isso Joyce também tem, uma contínua teorização da ficção, a todo momento, desde o início. Aquele rolar viconiano, ele reflete sobre isso e faz o romance. Então é um lugar em que a teoria e a prática se misturam. Quer dizer, faço isso com mais intensidade do que fazia antes. Mas como minha preocupação com Joyce é desde os anos 1960, sempre estive interessado pela sua linguagem. 
CT: Gostaríamos que você comentasse sobre o seu o último livro, Joyce era louco?, publicado pela Ateliê Editorial.

$D S$ : Bem, Lacan é um psicanalista francês ele é freudiano, mas ele reelabora o sistema freudiano. Pois bem, ele tinha entre de 17 a 20 anos (essa data não é bem precisa porque existem contradições) em que ele ouvia leituras públicas da tradução ao francês do Ulysses, e isso marcou Lacan definitivamente. Ele trabalhou na sua tese de doutorado, de 1933, que entre outras coisas aproximou seus pacientes esquizofrênicos com o surrealismo francês. E foi um dos primeiros autores que valorizou o movimento surrealista. Os surrealistas foram rejeitados quando apareceram... Ele foi um dos primeiros que alertou para o caráter criativo do surrealismo. Pois bem, ele foi influenciado por Joyce nas palavras que ele cria.

Por exemplo, condimento em francês é condiment, se escreve condiment. Lacan não escreve condiment assim, mas escreve "Qu'on dit ment", isso significa aquilo que se diz mente. Porque o que se diz, mente. Porque tudo o que nós falamos é mentira. É mentira porque a palavra não traduz nem os sentimentos e nem a realidade, sempre há uma distância entre aquilo que se diz e a realidade que se pretende dizer. Portanto mentimos sempre e essa mentira é um condimento. Quer dizer que existem mentiras, inclusive mentiras literárias, que são mentiras condimentadas. Então, é um conceito que Lacan cria e usa psicanaliticamente, inclusive na análise, isto é, estudar um paciente que vai a sessão, ele mente. Lacan trabalha com essa mentira, ou seja, a verdade existe dentro dessa mentira. Por isso, "Qu'on dit ment" é um processo nitidamente joyciando. Nos anos de 1975, houve um congresso Joyciano em Paris e Lacan foi convidado a proferir a palestra inicial, estando em contato com joycistas e leu sobre Joyce, etc. Terminado o congresso, ele realizou um seminário... Seminários ele realizou durante toda a sua atividade. O seminário 23 foi um seminário de um ano que ele dedicou a Joyce. A pergunta dele, que é uma pergunta já de 1933, presente na sua tese de doutorado: qual a diferença entre uma anomalia como a esquizofrenia, com a literatura? Enfim, essa criação

Cad. Trad., Florianópolis, v. 39, no 2, p. 294-304, mai-ago, 2019. 
de palavras... inclusive a filha dele, a Lucia, ela ouvia vozes e quando Joyce percebeu essa anomalia, ele julgava que ela era genial. Há uma pergunta que Lacan faz no ensaio, Joyce era louco? Quer dizer, qual o limite entre a criação literária e a loucura? Nesse livro, procuro analisar essas situações, ele leva inclusive a uma teoria literária. Aproveitei, então, essa pergunta que Lacan faz e coloquei no título do livro: Joyce era louco? Onde entra toda essa questão.

\section{Referência}

Schüler, Donaldo. "Donaldo Schüler em Torno a Tradução e o Finnegans Wake". Scientia Traductionis, Florianópolis, 313-24 n.8, 2010. Entrevista concedida a Marie-Hélène Torres e Mauri Furlan.

Recebido em: $12 / 12 / 2018$ Aceito em: 18/03/2019

Publicado em maio de 2019

Leide Daiane de Almeida Oliveira. E-mail: daiane.deao@gmail.com. ORCID: https://orcid.org/0000-0001-5618-445X

Larissa Ceres Lagos. E-mail: lariceres@gmail.com. ORCID: https://orcid. org/0000-0001-8275-4196

Giovana Beatriz Marique Ursini. E-mail: giovana_ursini@hotmail.com. ORCID: https://orcid.org/0000-0002-5373-9269 